EXTENDED REPORT

\title{
Prognostic factors for remission in early rheumatoid arthritis: a multiparameter prospective study
}

\author{
L Gossec, M Dougados, P Goupille, A Cantagrel, J Sibilia, O Meyer, J Sany, J-P Daurès, B Combe
}

Ann Rheum Dis 2004;63:675-680. doi: 10.1136/ard.2003.010611

See end of article for authors' affiliations

......

Correspondence to: Professor Bernard Combe, Service d'ImmunoRhumatologie, Hôpital Lapeyronie, 371 Avenue du doyen Gaston Giraud 34295 Montpellier Cedex 5, France; b-combe@ chu-montpellier.fr

Accepted 22 July 2003
Objective: To determine prognostic factors for remission in early rheumatoid arthritis.

Methods: 191 patients with rheumatoid arthritis whose disease duration was less than one year were followed up prospectively for five years. Remission, defined by a disease activity score (DAS) of $<1.6$, was used as the outcome measure. Baseline clinical, laboratory, genetic, and radiographic data (with radiographic scores determined by Sharp's method, modified by van der Heijde) were obtained.

Results: 48 patients (25.1\%) fulfilled the remission criteria at the three year follow up visit, and 30 (15.7\%) at three and five years. On univariate analysis by Fisher's exact test, remission at three years and persistent remission at five years were closely correlated with baseline DAS values, C reactive protein level, Ritchie score, health assessment questionnaire score, duration of morning stiffness, and to a lesser extent baseline total radiological scores and rheumatoid factor negativity. No significant correlation was found with sex, age, extra-articular manifestations, erythrocyte sedimentation rate, anti-cyclic citrullinated protein antibodies, anti-keratin antibodies, anti-HSP 90, anticalpastatin antibodies, antinuclear antibodies, or HLA-DRB1* genotypes. Logistic regression analysis showed that the baseline independent variables predictive of remission were low DAS, Ritchie score, morning stiffness duration, and total radiographic score.

Conclusions: Baseline prognostic factors for remission in early rheumatoid arthritis were mainly clinical markers of disease activity and radiological scores.
$\mathrm{R}$ heumatoid arthritis is currently recognised as a heterogeneous entity that is usually diagnosed with reference to the American College of Rheumatology (ACR) classification criteria. ${ }^{1}$ The clinical course of rheumatoid arthritis is variable and its prognosis is difficult to predict. $^{2}{ }^{3}$ In many patients, the disease process is severe and results in progressive joint destruction and serious disability, but outcomes vary widely. Predicting the outcome of this disease is crucial for optimal clinical management. Patients with a high likelihood of an untoward outcome should be given appropriately aggressive treatment at an early stage; this is even more important now that new treatments have been shown to reduce progression of the disease. ${ }^{4-6}$ The ultimate goal of treatment is remission-that is, complete suppression of disease activity. ${ }^{7}$ The American Rheumatism Association (ARA) has defined preliminary remission criteria. ${ }^{8}$ These criteria are based on six variables, of which two (fatigue and joint pain on motion) are not included in the core sets of variables uniformly collected in clinical studies. ${ }^{9}$ Prevoo et al proposed the disease activity score $\left(\mathrm{DAS}^{10}\right)$ as a standardised evaluation tool to define remission, after showing in 227 patients that those with a DAS of $<1.6$ were in remission according to the ARA criteria. ${ }^{11}$

Remission is a pertinent outcome measure in rheumatoid arthritis, yet few studies have attempted to determine prognostic factors for remission. It has been claimed that if remission does occur, it tends to happen early; thus it is important to study patients in the early stages of the disease.

In the present prospective study, we investigated various clinical, laboratory, genetic, and radiographic indices in a cohort of patients with early rheumatoid arthritis. We evaluated remission rates (using the DAS) after three and five years of follow up and analysed prognostic factors for remission at three years, and for sustained three year and five year remission.

\section{METHODS}

\section{Patients}

Between March 1993 and October 1994, we recruited consecutive outpatients referred by primary care physicians for the purposes of the study from four French centres (Montpellier, Paris-Cochin, Toulouse, and Tours) who fulfilled the ACR criteria for rheumatoid arthritis, ${ }^{1}$ had a disease duration of less than one year, and had not previously been treated with disease modifying antirheumatic drugs (DMARDs). All patients agreed to be enrolled in a five year follow up study and provided their signed informed consent. They were subsequently treated with DMARDs (usually methotrexate, sulphasalazine, or a combination of both), and the regimen could be modified during the study according to efficacy and tolerance.

The study was approved by the ethics review board in Montpellier.

\section{Clinical and biological assessment}

The following evaluation data were collected at baseline: age; sex; body mass index; disease duration; duration of morning stiffness; patients' assessment of pain (on a visual analogue scale); number of swollen and tender joints; Ritchie articular index ${ }^{12}$; disease activity score; presence or absence of nodules and extra-articular manifestations; health assessment questionnaire (HAQ) score ${ }^{13}$; erythrocyte sedimentation rate (ESR); C reactive protein concentration; $\operatorname{IgA}$ and $\operatorname{IgM}$ rheumatoid factor (RF) positivity by anti-human Fc IgG enzyme linked immunosorbent assay (ELISA); antikeratin

Abbreviations: ACR, American College of Rheumatology; ARA, American Rheumatism Association, DAS, disease activity score; $D M A R D$, disease modifying antirheumatic drug; $H A Q$, health assessment questionnaire 
antibody positivity by indirect immunofluorescence on cryostat sections of rat oesophagus; anti-cyclic citrullinated protein (CCP) antibody positivity by ELISA ${ }^{14}$; antiperinuclear antibody positivity by immunofluorescence on buccal epithelial cells; anti-RA33 antibody positivity by immunoblotting ${ }^{15}$; anti-heat-shock protein $90 \mathrm{kDa}$ antibody positivity by ELISA $^{16}$; anticalpastatin antibody positivity by ELISA (Progen, Heidelberg, Germany); serum concentration of YKL-40 by radioimmunoassay (Chondrex Metra Biosystems, Mountain View, California, USA); and antinuclear antibody positivity by immunofluorescence on Hep-2 cells. HLA-DRB 1 and DQBI genotyping were done as previously described.$^{17}$ Each patient was followed up by the same investigator (BC, $\mathrm{MD}, \mathrm{PG}$, or $\mathrm{AC}$ ) at six months after inclusion, at one year, and then after three and five years. ${ }^{17} 18$

\section{Radiographic assessment}

Hand, wrist, and foot radiographs were obtained at baseline and at three and five years. They were evaluated blind and in chronological order by two independent observers and scored using Sharp's method as modified by van der Heijde. ${ }^{19}$ For each patient, an erosions score, a joint space narrowing score, and a total damage score were noted for the hands and feet. The intraclass, intraobserver, and interobserver coefficients of correlation were calculated on 30 chosen pairs of radiographs of the hands and feet and were always greater than 0.85 . No systematic differences were found in any of the scores. We then used the mean of the two observer scores to determine the final radiographic scores for erosions, joint space narrowing, and total damage.

\section{Outcome measurement}

Remission was defined by a DAS of $<1.6$ at the three year follow up visit, according to Prevoo et al. ${ }^{11}$ Persistent remission was defined by a DAS of $<1.6$ at the three year and five year evaluations.

\section{Statistical methods}

Statistical analysis was done using BMDP statistical software. ${ }^{20}$ The outcome variable was treated as a qualitative variable: the presence or absence of remission. Univariate analysis of the relation between all baseline values and the outcome measure was undertaken using the $\chi^{2}$ test, with Yates' correction when appropriate, or Fisher's exact test. When these variables were continuous, they were transformed into categorical variables using the median value as the cut off point, except for ESR, where the cut off was chosen according to clinical experience (a cut off of $28 \mathrm{~mm} /$ hour). Odds ratios with $95 \%$ confidence intervals (CI) were estimated by the Mantel-Haenszel method.

A stepwise multiple logistic regression model was used to find relevant independent prognostic variables. The variables included in the multivariate model were selected using univariate analysis $(p \leqslant 0.15)$. The significance level was set at 0.05 .

\section{RESULTS}

\section{Demographic, clinical, and biological features of the} patient cohort

The baseline characteristics of the patients are shown in table 1. We enrolled 191 patients in the study (140 women, 51 men). Their mean (SD) age at diagnosis was 50.5 (14.7) years and the mean disease duration at inclusion was 3.3 (2.6) months. Of these, $154(80.6 \%)$ were IgM or IgA RF positive $(\geqslant 20 \mathrm{IU} / \mathrm{ml}$ and $\geqslant 7$ units $/ \mathrm{ml}$, respectively) at baseline, and $86(45 \%)$ had at least one rheumatoid arthritis associated DRB1*04 allele (DRB1*0401, 0404, 0405, or 0408). Six months after inclusion, 178 patients (93.2\%) were taking DMARDs: 131 (68.6\%) were taking one drug (58 methotrex-
Table 1 Characteristics of 191 patients with rheumatoid arthritis

\begin{tabular}{|c|c|}
\hline Sex, \% women & $73.3 \%$ \\
\hline Age at diagnosis (years) & $50.5(14.7)$ \\
\hline Duration of disease (months) & $3.3(2.6)$ \\
\hline Morning stiffness (min) & $84(79.4)$ \\
\hline \multicolumn{2}{|c|}{ Patient's assessment of pain (visual analogue scale) } \\
\hline$(\mathrm{mm})$ & $57.5(22.2)$ \\
\hline Swollen joints (number) & $9.0(5.9)$ \\
\hline Tender joints (number) & $21(10)$ \\
\hline Ritchie score & $17.5(8.5)$ \\
\hline HAQ score & $1.3(0.7)$ \\
\hline DAS & $4.1(0.8)$ \\
\hline Extra-articular manifestations (\% patients) & $8.4 \%$ \\
\hline $\mathrm{ESR}(\mathrm{mm} / \mathrm{h})$ & $40.2(28.5)$ \\
\hline $\mathrm{C}$ reactive protein $(\mathrm{mg} / \mathrm{l})$ & $34.1(43.2)$ \\
\hline RF positivity (\% patients) & $80.8 \%$ \\
\hline $\lg M \operatorname{RF}(\%)$ & $68.0 \%$ \\
\hline IgA RF (\%) & $75.5 \%$ \\
\hline \multicolumn{2}{|l|}{ Antibody positivity, $\%$ patients } \\
\hline Anti-CCP & $58.9 \%$ \\
\hline Antiperinuclear & $49.9 \%$ \\
\hline Antikeratin & $41.4 \%$ \\
\hline Anticalpastatin & $16.5 \%$ \\
\hline Antinuclear & $36 \%$ \\
\hline Anti-HSP9O & $23.0 \%$ \\
\hline Anti-RA33 & $27.2 \%$ \\
\hline YKL40 serum concentration (ng/ml) & $109.7(79.9)$ \\
\hline HLA-DRB 1 *04 (\% patients)† & $47.6 \%$ \\
\hline HLA-DRB 1 ${ }^{*} 01$ (\% patients) & $29.5 \%$ \\
\hline Total Sharp score at baselineł & $3.6(7.7)$ \\
\hline \multicolumn{2}{|c|}{$\begin{array}{l}\text { Values are the mean (SD) unless stated otherwise. } \\
\text { Positive cut off values were as follows: IgM rheumatoid factor (RF), } \geqslant 20 \\
\mathrm{IU} / \mathrm{ml} \text {; IgA RF, } \geqslant 7 \text { units } / \mathrm{ml} \text {; antiperinuclear antibodies, } \geqslant 1: 20 ; \text { anti- } \\
\text { cyclic citrullinated protein antibodies, } \geqslant 50 \text { units } / \mathrm{ml} \text {; antikeratin } \\
\text { antibodies, } \geqslant 1: 80 \text {; anticalpastatin antibodies, } \geqslant 15 \text { units } / \mathrm{ml} \text {; antinuclear } \\
\text { antibodies, } \geqslant 1: 160 \text {. } \\
\text { Anti-CCP, anti-cyclic citrullinated protein; anti-HSP } 90 \text {, anti-heat-shock } \\
\text { protein } 90 \mathrm{kDa} \text { antibodies; DAS, disease activity score; ESR, erythrocyte } \\
\text { sedimentation rate; } \mathrm{HAQ}, \text { health assessment questionnaire; RF, } \\
\text { rheumatoid factor. } \\
+D R B 1 * 04 \text { includes } \mathrm{DRB} 1{ }^{*} 0401,0404,0405 \text {, and } 0408 \text {. } \\
\pm \text { Total damage score on radiographic evaluation of the hands and feet. }\end{array}$} \\
\hline
\end{tabular}

ate, 59 sulphasalazine, 14 other DMARDs), and 47 (24.6\%) a combination of methotrexate and sulphasalazine. During the five year follow up, a mean of 1.95 DMARDs (range one to five) were prescribed (methotrexate to 175 patients, sulphasalazine to 147 , intramuscular gold to 41 , hydroxychloroquine to 25 , D-penicillamine to 14 , cyclosporin to one). Eighty six patients received the same DMARD or the same combination of DMARDs during the five year follow up. Sixty three patients $(33 \%)$ received a low dose of prednisone (5-15 $\mathrm{mg}$ /day) at least once during follow up.

\section{Remission rate}

Fourteen patients $(7.3 \%)$ were lost to follow up at three years. At five years, 26 patients (13.6\%) were lost to follow up (six died, eight refused further follow up, 12 moved out of the area) and $31(16.2 \%)$ had missing data at the five year evaluation and were excluded from the analysis. The baseline characteristics of these patients did not differ from those of the rest of the cohort except for higher antikeratin antibody positivity $(\mathrm{p}=0.03)$ in the patients with missing data.

Forty eight patients $(25.1 \%)$ fulfilled the remission criteria at the three year follow up visit, 38 (19.9\%) at the five year follow up visit, and $30(15.7 \%)$ at both visits; $78.9 \%$ of patients in remission at three years were also in remission at five years (odds ratio 32.2, $\mathrm{p}<0.00001$ ).

\section{Predictive variables identified by the univariate analysis}

The results obtained by univariate analysis of the studied baseline variables are presented in table 2 for three year 
Table 2 Factors predictive of remission at three years

\begin{tabular}{lll}
\hline Baseline variable & $\mathbf{p ~ V a l u e *}$ & OR $(95 \% \mathrm{CI})^{*}$ \\
\hline DAS $<4$ & 0.0009 & $3.2(1.6$ to 6.5$)$ \\
HAQ score $<1.25$ & 0.0087 & $2.8(1.3$ to 6.4$)$ \\
Ritchie score $<17$ & 0.019 & $2.29(1.1$ to 4.6$)$ \\
C reactive protein $<14.5 \mathrm{mg} / \mathrm{l}$ & 0.041 & $2(1.0$ to 4.1$)$ \\
Morning stiffness $<60 \mathrm{~min}$ & 0.051 & $2.1(0.98$ to 4.8$)$ \\
Total Sharp score $<4$ & 0.053 & $1.99(0.98$ to 4.0$)$ \\
Anti-HSP90 negativity & 0.057 & $2.6(0.94$ to 7.3$)$ \\
Erosion score $=0$ & 0.062 & $1.97(0.95$ to 4$)$ \\
Tender joint count $<21$ & 0.069 & $2(0.94$ to 4.3$)$ \\
Pain on visual analogue scale & & \\
$<59$ mm & 0.085 & $1.94(0.9$ to 4.1$)$ \\
lgA RF negativity & 0.14 & $1.75(0.8$ to 3.8$)$ \\
No extra-articular manifestations & 0.15 & $2.89(0.6$ to 13$)$ \\
Anticalpastatin antibody negativity & 0.18 & $0.54(0.2$ to 1.3$)$ \\
lgM RF negativity & 0.41 & $1.34(0.65$ to 2.8$)$ \\
Swollen joint count $<9$ & 0.54 & $1.2(0.6$ to 2.5$)$ \\
ESR $<28$ mm/h & 0.77 & $1.1(0.56$ to 2.1$)$ \\
Antikeratin antibody negativity & 0.82 & $1.08(0.5$ to 2.2$)$ \\
HLA-DRB1 *01 negativity & 0.81 & $0.91(0.4$ to 2.3$)$ \\
HLA-DRB1*04 negativity & 0.88 & $0.95(0.5$ to 1.8$)$ \\
Anti-CCP antibody negativity & 0.95 & $1.02(0.4$ to 2.2$)$ \\
\hline
\end{tabular}

*Significance level calculated using the $\chi^{2}$ with Yates' correction. †DRB 1*04 includes *0401, 0404, 0405, and 0408.

Anti-CCP, anti-cyclic citrullinated protein; $\mathrm{Cl}$, confidence interval; DAS, disease activity score; $E S R$, erythrocyte sedimentation rate; $H A Q$, health assessment questionnaire; OR, odds ratio; RF, rheumatoid factor.

remission. Baseline disease activity scores were the best predictive factors for remission. An initial DAS of $<4$ was the best predictor $(\mathrm{p}<0.001)$; an HAQ score $<1.25$, a Ritchie score $<17$, and a $\mathrm{C}$ reactive protein concentration of $<14.5$ $\mathrm{mg} / \mathrm{l}$ were also significantly correlated with remission. Morning stiffness $(p=0.051)$, total Sharp score $(p=0.053)$, anti-HSP90 negativity $(p=0.057)$, erosion score $(p=0.062)$, and tender joint count $(\mathrm{p}=0.069)$ showed a trend towards association with remission. Univariate analysis of predictive factors for persistent three and five year remission is presented in table 3. A baseline DAS of $<4$, an HAQ score of $<1.25$, a Ritchie score of $<17$, a $\mathrm{C}$ reactive protein concentration of $<14.5 \mathrm{mg} / \mathrm{l}$, a total Sharp score of $<4$ points,

Table 3 Predictive factors for persistent remission (DAS $<1.6$ at the three year and five year evaluations)

\begin{tabular}{lll}
\hline Baseline variable & p Value* & OR $(95 \%$ Cl)* \\
\hline DAS $<4$ & 0.0003 & $4.8(1.9$ to 11.9$)$ \\
C reactive protein $<14.5 \mathrm{mg} / \mathrm{I}$ & 0.010 & $3(1.2$ to 7.3$)$ \\
Ritchie score $<17$ & 0.016 & $2.8(1.2$ to 6.8$)$ \\
$\mathrm{HAQ}$ score $<1.25$ & 0.018 & $3.2(1.1$ to 8.9$)$ \\
IgM RF negativity & 0.02 & $2.6(1.1$ to 6.3$)$ \\
Morning stiffness $<60$ min & 0.04 & $2.7(1.0$ to 7.4$)$ \\
Total Sharp score $<4$ & 0.04 & $2.3(1.0$ to 5.7$)$ \\
Anti-HSP90 negativity & 0.06 & $3.2(0.9$ to 11.4$)$ \\
IgA RF negativity & 0.10 & $2(0.85$ to 5.1$)$ \\
Pain on visual analogue scale & & \\
$<59$ mm & 0.13 & $2(0.8$ to 5.0$)$ \\
Antikeratin antibody negativity & 0.16 & $1.94(0.75$ to 5.0$)$ \\
Tender joint count $<21$ & 0.19 & $1.8(0.7$ to 4.6$)$ \\
Anticalpastatin antibody negativity & 0.29 & $0.58(0.2$ to 1.3$)$ \\
Swollen joint count $<9$ & 0.51 & $1.3(0.57$ to 3.0$)$ \\
ESR $<28$ mm/h & 0.56 & $1.2(0.5$ to 2.9$)$ \\
Anti-CCP antibody negativity & 0.62 & $1.25(0.5$ to 4.7$)$ \\
YKL40 negativity $\dagger$ & 0.74 & $0.7(0.07$ to 6.3$)$ \\
Erosion score $=0$ & 0.8 & $2.18(0.9$ to 5.3$)$ \\
HLA-DRB ${ }^{*} 01$ negativity & 0.8 & $0.89(0.36$ to 2.2$)$ \\
HLA-DRB1 ${ }^{*} 04$ negativity $\ddagger$ & 0.9 & $1.05(0.5$ to 2.4$)$ \\
\hline
\end{tabular}

*Significance level calculated using the $\chi^{2}$ test with Yates' correction. †Range $24-125 \mathrm{ng} / \mathrm{ml}$.

fDRB 1*04 includes *0401, 0404, 0405, and 0408 .

Anti-CCP, anti-cyclic citrullinated protein; $\mathrm{Cl}$, confidence interval; DAS, disease activity score; $E S R$, erythrocyte sedimentation rate; $H A Q$, health assessment questionnaire; $O R$, odds ratio; $R F$, rheumatoid factor. duration of morning stiffness $<60$ minutes, and RF negativity were correlated with persistent three and five year remission. No association was noted for any other variable, including age, sex, antikeratin or anti-CCP antibody negativity, and rheumatoid arthritis associated HLA-DRBl genes.

\section{Stepwise multiple logistic regression}

Tables 4 and 5 give the entry parameters identified by the multivariate logistic regression models that were independently predictive of the presence of remission at three years, and of persistent remission at the three year and five year evaluations.

Low DAS, baseline total radiographic score, and Ritchie score were the most important factors determining remission both at three years and in the "sustained remission" analysis. A low HAQ score and short duration of morning stiffness were predictive of remission at three years. A low baseline $C$ reactive protein concentration was predictive of persistent remission.

\section{DISCUSSION}

This multiparameter prospective study of a cohort of outpatients with early rheumatoid arthritis (less than one year disease duration) identified predictive factors of three year remission and sustained three and five year remission. The outcome variable was remission as defined by a disease activity score of $<1.6 .{ }^{11}$ Univariate analysis tested most of the clinical, biological, immunological, and genetic factors previously reported as possible prognostic factors in rheumatoid arthritis. Analysis was done on baseline variables. Remission was correlated with low baseline DAS, HAQ score, Ritchie score, and $\mathrm{C}$ reactive protein concentration. Logistic regression analysis showed that the only independent variables that were significant predictors of both three year and sustained remission were low DAS, baseline total radiographic score, and Ritchie score.

The prevalence of remission is variable between studies, perhaps because there is still no universally accepted definition of remission. The preliminary ARA criteria ${ }^{8}$ are not sufficiently precise, and are not all core measures in the follow up of patients with rheumatoid arthritis. Methods of patient referral and selection vary between studies, as well as the duration without symptoms used to define remission. All in all, comparisons between studies concerning remission rates are difficult. We evaluated remission as a dichotomous variable at one point in time: the three year follow up visit. We then evaluated how many of our patients were in remission both at the three year and the five year evaluation, and predictive factors of this "sustained" remission. The ARA preliminary criteria defined remission with a notion of time period (two months). This aspect was not investigated in the original study ${ }^{8}$ or in the studies by Wolfe and Hawley ${ }^{21}$ and Alarçon et al, ${ }^{22}$ because their follow up was not standardised. The DAS was evaluated as a definition criterion for remission using a three month time period, ${ }^{11}$ while Eberhardt and Fex used the ARA criteria but over a six month period. ${ }^{23}$ Other studies looked at remission as a state at one point in time..$^{21} 2224$

We found that $25.1 \%$ of our patients were in remission after three years, $19.9 \%$ after five years, and $15.7 \%$ at both evaluations. Prevoo et al studied 227 patients with a median follow up of 3.9 years $^{11}$; the percentage of patients with at least one visit fulfilling the ARA remission criteria was 25\%; each year, $15 \%$ of the patients were in remission for at least two consecutive visits. Eberhardt and $\mathrm{Fex}^{23}$ found that $20 \%$ of 183 patients achieved ARA defined remission periods of at least six months' duration; average length of remission was 20.5 months. In Wolfe and Hawley's study ${ }^{21}$ of 458 patients with rheumatoid arthritis, with established disease and at 
Table 4 Stepwise logistic regression analysis of predictive factors of remission at three years

\begin{tabular}{|c|c|c|c|c|}
\hline & Coefficient & SE & OR $(95 \% \mathrm{CI})$ & $p$ Value \\
\hline \multicolumn{5}{|l|}{ With DAS } \\
\hline Constant & -2.8 & 0.5 & 0 & \\
\hline $\mathrm{DAS}<4$ & 1.75 & 0.4 & 5.7 (2.3 to 14.2 ) & $<0.0001$ \\
\hline Initial Sharp score $<4^{*}$ & 1.05 & 0.4 & $2.9(1.3$ to 7.0$)$ & 0.017 \\
\hline Morning stiffness $<60 \mathrm{~min}$ & 1.91 & 0.5 & $2.5(0.9$ to 6.6$)$ & 0.056 \\
\hline \multicolumn{5}{|l|}{ Without DAS } \\
\hline Constant & -0.79 & 0.4 & & \\
\hline $\mathrm{HAQ}<1.25$ & 0.83 & 0.4 & $2.3(0.9$ to 5.7$)$ & 0.06 \\
\hline Initial Sharp score $<4^{*}$ & 1.06 & 0.4 & $2.9(1.2$ to 7.0$)$ & 0.01 \\
\hline Ritchie score $<17$ & 1.01 & 0.4 & $2.7(1.1$ to 6.7$)$ & 0.02 \\
\hline Morning stiffness $<60 \mathrm{~min}$ & -0.82 & 0.5 & $2.3(0.9$ to 6.0$)$ & 0.08 \\
\hline
\end{tabular}

least three follow up visits, $18.1 \%$ fulfilled the ARA criteria once. In a French cohort, remission was obtained in $10.5 \%$ of patients, but in only $5 \%$ by the ARA criteria. ${ }^{25}$ Our rate of remission is in the higher range of published results, perhaps because we used Prevoo's definition of remission, which may be less stringent than the ARA criteria. On the other hand, our patients presented with rheumatoid arthritis according to ACR criteria (while many other studies were done on patients with undifferentiated arthritis). Our patients were referred to tertiary care departments, often a criterion of severity; but in this study we asked primary care physicians to refer all their patients presenting with early arthritis, without selection on the basis of severity, so that theoretically our cohort reflects community based early rheumatoid arthritis severity. The highest cross sectional (one visit) rate of remission was found in a Finnish study, ${ }^{24}$ where $27 \%$ of the patients were in ARA defined remission at the two year follow up and $32 \%$ at the six year follow up. That study involved 142 patients with early rheumatoid arthritis treated with DMARDs. Harrison et $a l^{26}$ in a community based rheumatoid arthritis cohort, found $19 \%$ in remission after two years, remission being defined as "no arthritis on examination and no DMARD or steroid treatment within the previous three months." Two other studies reported a cross sectional remission rate of around $7 \%$ after three and seven years, respectively. ${ }^{27}{ }^{28}$ Both studies used "being symptom-free" as a definition of remission.

We found that clinical markers of disease activity were the main predictors of remission. Some other studies have attempted to identify factors measured close to disease onset that might be used to predict future remission. Recent studies $^{29}{ }^{30}$ have like ours identified mainly clinical markers as predictive of remission. Eberhardt et al also identified a lower HAQ score as predictive. ${ }^{31}$

We found no association of sex or age with remission. In Wolfe and Hawley's study, ${ }^{21}$ female sex, onset before the age of 60 years, and early development of erosions were associated with fewer remission periods. Harrison et al confirmed this finding of an association with sex but not age. ${ }^{26}$ Like us, they found an association with less widespread joint involvement at baseline.

To our knowledge, we are the first to have looked at the correlation between radiographic scores and remission. In multivariate analysis, a baseline total Sharp score (as modified by van der Heijde) of less than 4 points was predictive of remission in our study. Conversely, in a prospective study Möttönen et al found that patients who having at least once remission had less radiological damage after six years, with the lowest progression of radiological damage in those in remission at both evaluation points (two years and six years). ${ }^{24}$

Other studies have reported that being RF negative is important for remission. In our work, RF status was correlated with persistent remission in univariate analysis (odds ratio 2.6). We found no predictive value of antikeratin or anti-CCP antibody negativity.

The influence of rheumatoid arthritis associated HLADRBl alleles is controversial. Molenaar et al, ${ }^{32}$ like us, found no association between remission (ARA criteria) ${ }^{8}$ and HLADRBI alleles or DR/DQ haplotypes in 167 patients. Similarly, Möttönen et al found that the presence of a shared epitope had no impact on remission rates in 165 patients. ${ }^{33}$ Other workers found the opposite. ${ }^{34}{ }^{35}$ In Eberhardt's prospective

Table 5 Stepwise logistic regression analysis of predictive factors of persistent remission (DAS $<1.6$ at the three year and five year evaluations)

\begin{tabular}{|c|c|c|c|c|}
\hline & Coefficient & SE & OR $(95 \% \mathrm{Cl})$ & $\mathrm{p}$ Value \\
\hline \multicolumn{5}{|l|}{ With DAS } \\
\hline Constant & -0.88 & 0.5 & & \\
\hline DAS $<4$ & 1.7 & 0.6 & $5.5(1.7-17.8)$ & $<0.0001$ \\
\hline Initial Sharp score $<4^{*}$ & 1.07 & 0.5 & $2.7(0.9-8.1)$ & 0.02 \\
\hline$C$ reactive protein $<14.5 \mathrm{mg} / \mathrm{l}$ & 0.9 & 0.5 & $2.5(0.8-7.4)$ & 0.09 \\
\hline \multicolumn{5}{|l|}{ Without DAS } \\
\hline Constant & -1.03 & 0.5 & & \\
\hline$C$ reactive protein $<14.5 \mathrm{mg} / \mathrm{l}$ & 1.14 & 0.5 & $3.1(1.0-9.0)$ & 0.004 \\
\hline Ritchie score $<17$ & 1.4 & 0.6 & $4.2(1.4-12.8)$ & 0.012 \\
\hline Initial Sharp score $<4^{*}$ & 1.01 & 0.5 & $2.7(0.9-8.0)$ & 0.05 \\
\hline
\end{tabular}


study, ${ }^{23}$ remission was more likely in seronegative patients having no shared epitopes or only a single one and fewer active joints at baseline.

The potential role of DMARD treatment was not evaluated in our study, because our cohort was DMARD-naive at baseline, and then treated in a highly homogeneous way, mostly with methotrexate or sulphasalazine or both, prescribed less than six months after inclusion. This renders comparisons between subgroups irrelevant. Furthermore, clinical and radiological status was shown to be similar after 18 months of treatment with either methotrexate, sulphasalazine, or a combination of both, ${ }^{36}$ making it unlikely that the different drug regimens could have induced different remission rates in our study. For Möttönen et al, ${ }^{37}$ remission was predicted by treatment strategy: patients treated with a combination of DMARDs had a higher remission rate than those treated with monotherapy. The same investigators reported that a shorter delay before DMARD institution was predictive of remission for patients treated with a single DMARD, while this delay did not contribute to the induction of remission in those treated with combination DMARDs. ${ }^{38}$ Verstappen et al recently confirmed similar remission rates but a shorter delay before first remission with more aggressive DMARDs. ${ }^{30}$

We did not study the implications of remission on disability and joint damage, but Eberhardt and $\mathrm{Fex}^{23}$ found that outcome was worse for patients presenting with progressive rheumatoid arthritis than for those with a relapsing-remitting disease pattern; and Molenaar et al found that in patients with rheumatoid arthritis and inactive disease, functional disability is slight and most strongly associated with pain, joint damage, disease duration, and disease activity. ${ }^{39}$ Thus remission appears to be a valuable outcome measurement in rheumatoid arthritis, with a clinical impact. However, in all the published studies, including ours, the factors identified are not strong enough to make accurate predictions of remission, even when used in combination.

In conclusion, prognostic factors for remission in early rheumatoid arthritis are mainly the baseline disease activity score, clinical markers of disease activity, and baseline radiological scores.

\section{ACKNOWLEDGEMENTS}

We thank M-C Bozonnat for kindly helping with the statistical analysis and A Dubois for expert radiological assessment. Supported by a grant from the Direction de la Recherche Clinique, Centre Hospitalier Montpellier (France).

\section{Authors' affiliations}

L Gossec, M Dougados, René Descartes University, Cochin Hospital, Department of Rheumatology B, Paris, France

P Goupille, Centre Hospitalier Universitaire Tours, Tours, France

A Cantagrel, Centre Hospitalier Universitaire Rangueil, Toulouse, France

J Sibilia, Centre Hospitalier Universitaire Strasbourg, Strasbourg, France

O Meyer, Centre Hospitalier Universitaire Bichat, Paris, France

J Sany, B Combe, service d'Immuno-Rhumatologie, Centre Hospitalier Universitaire Montpellier, and INSERM U454, Montpellier, France J-P Daurès, Institut Universitaire de Recherche Clinique, Montpellier, France

\section{REFERENCES}

1 Arnett FC, Edworthy SM, Block DA, McShane DJ, Fries JF, Cooper NS. The American Rheumatism Association 1987 revised criteria for the classification of rheumatoid arthritis. Arthritis Rheum 1988;31:315-24.

2 Scott DL, Symmons DP, Coulton BL, Popert AJ. Long-term outcome of treating rheumatoid arthritis: results after 20 years. Lancet 1987;i: $1108-11$.

3 Pope RM. Rheumatoid arthritis: pathogenesis and early recognition. Am J Med 1996; 100:3-9S

4 Smolen JS, Kalden JR, Scott DL, Rozman B, Kvien TK, Larsen A, et al. Efficacy and safety of leflunomide compared with placebo and sulphasalazine in active rheumatoid arthritis: a double-blind, randomized, multicenter trial Lancet 1999;353:259-66.

5 Weinblatt ME, Kremer JM, Bankhurst AD, Bulpitt KJ, Fleischmann RM, Fox RI, et al. A trial of etanercept, a recombinant tumor necrosis factor receptor: Fc fusion protein in patients with rheumatoid arthritis receiving methotrexate. N Engl J Med 1999;340:253-9.

6 Maini R, St Clair EW, Breedveld F, Furst D, Kalden J, Weisman M, et al. Infliximab (chimeric anti-tumour necrosis factor alpha monoclonal antibody) versus placebo in rheumatoid arthritis patients receiving concomitant methotrexate: a randomised phase III trial. Lancet 1999;354:1932-9.

7 WHO. Proceedings of Vth joint World Health Organisation and International League of Associations for Rheumatology task force meeting on rheumatic diseases, Geneva, 29 June-2 July 1993. J Rheumatol 1994;21(suppl): 1-89.

8 Pinals RS, Masi AT, Larsen RA. Preliminary criteria for clinical remission in rheumatoid arthritis. Arthritis Rheum 1981;24:1308-15.

9 Wolfe F, Lassere M, van der Heijde D, Stucki G, Suarez-Almazor M, Pincus T, et al. Preliminary core set of domains and reporting requirements for longitudinal observational studies in rheumatology. J Rheumatol 1999:26:484-9.

10 van der Heijde D, van't Hof M, Van Riel P, Van de Putte LBA. Development of a disease activity score based on judgment in clinical practice by rheumatologists. J Rheumatol 1993;20:579-81.

11 Prevoo MLL, van Gestel AM, van't Hof M, van Rijswijk MH, van de Putte LBA, van Riel P. Remission in a prospective study of patients with rheumatoid arthritis. American Rheumatism Association criteria in relation to the disease activity score. Br J Rheumatol 1996;35:1101-5.

12 Ritchie DM, Boyle JA, Mclnnes JM, Jasani MK, Dalakos TG, Grieveson P, et al. Clinical studies with an articular index for the assessment of joint tenderness in patients with rheumatoid arthritis. QJM 1968;37:393-406.

13 Fries JF, Spitz PW, Kraines RG, Holman HR. Measurement of patient outcome in arthritis. Arthritis Rheum 1980;23:137-45.

14 Meyer O, Labarre C, Dougados M, Goupille P, Cantagrel A, Dubois A, et al. Anticitrullinated protein/peptide antibody assays in early rheumatoid arthritis for predicting five year radiographic damage. Ann Rheum Dis 2003;62:120-6.

15 Meyer O, Tauxe F, Fabregas D, Gabay C, Goycochea M, Haim T, et al. AntiRA33 antinuclear antibody in rheumatoid arthritis and mixed connective tissue disease: comparison with antikeratin and antiperinuclear antibodies. Clin Exp Rheumatol 1993;11:473-8.

16 Hayem G, de Bandt M, Palazzo E, Roux S, Combe B, Eliaou JF, et al. Antiheat shock protein 70 and $90 \mathrm{kD}$ antibodies in sera of patients with rheumatoid arthritis. Ann Rheum Dis 1999;58:291-6.

17 Combe B, Eliaou JF, Daures JP, Meyer O, Clot J, Sany J. Prognostic factors in rheumatoid arthritis: comparative study of two subsets of patients according to severity of articular damage. $\mathrm{Br} J$ Rheumatol 1995;34:529-34.

18 Combe B, Dougados M, Goupille P, Cantagrel A, Eliaou JF, Sibilia J, et al. Prognostic factors for radiographic damage in early rheumatoid arthritis. Arthritis Rheum 2001;44:1736-43

19 van der Heijde D, van Riel P, Nuver-Zwart HH, van de Putte LBA. Effects of hydroxychloroquine and sulphasalazine on progression of joint damage in rheumatoid arthritis. Lancet 1989;i:1036-8.

20 Dixon WJ. BMDP statistical software manual, vol 2. Berkeley: University of California Press, 1988.

21 Wolfe F, Hawley DJ. Remission in rheumatoid arthritis. J Rheumatol 1985:12:245-52.

22 Alarçon GS, Blackburn WD, Calvo A, Castañeda O. Evaluation of the American Rheumatism Association preliminary criteria for remission in rheumatoid arthritis: a prospective study. J Rheumatol 1987;14:93-6.

23 Eberhardt K, Fex E. Clinical course and remission rate in patients with early rheumatoid arthritis: relationship to outcome after 5 years. $\mathrm{Br} J$ Rheumatol 1998;37:1324-9.

24 Möttönen T, Paimela L, Ahonen J, Helve T, Hannonen P, Leirisalo-Repo M. Outcome in patients with early rheumatoid arthritis treated according to the "sawtooth" strategy. Arthritis Rheum 1996;39:996-1005.

25 Mazieres B, Arlet J, Thalmann MD, Vidal R, Bismuth M. Remission dans la polyarthrite rhumatoïde: a propos de 32 cas. Rev Rhum Mal Osteoartic 1985:52:445-50.

26 Harrison B, Symmons D, Brennan P, Barrett E, Silman AJ. Natural remission in inflammatory polyarthritis: issues of definition and prediction. $\mathrm{Br} J$ Rheumatol 1996:35:1096-100

27 Nissilä M, Isomäki H, Kaarela K, Kiviniemi P, Martio J, Sarna S. Prognosis of inflammatory joint diseases. A three-year follow-up study. Scand J Rheumatol 1983; 12:33-8.

28 Wolfe F, Ross K, Hawley D, Roberts K, Cathey MA. The prognosis of rheumatoid arthritis and undifferentiated polyarthritis syndrome in the clinic: a study of 1141 patients. J Rheumatol 1993;20:2005-9.

29 Brown AK, Quinn MA, Karim Z, Wakefield RJ, Conaghan PG, Pollard AS, et al. Baseline clinical, functional and ultrasonographic assessment can be used to predict subsequent remission in rheumatoid arthritis [abstract]. Arthritis Rheum 2002;46(suppl):331.

30 Verstappen SM, Jacobs JW, Bijlsma JW. Number of early rheumatoid arthritis patients in remission: clinical features and prognostic factors [abstract]. Arthritis Rheum 2002;46(suppl):575.

31 Eberhardt KB, Rydgren LC, Pettersson H, Wollheim FA. Early rheumatoid arthritis - onset, course, and outcome over 2 years. Rheumatol Int 1990; 10:135-42. 
32 Molenaar ET Voskuyl AE, van der Horst-Bruinsma IE, Schreuder GM, Zanelli E, Dijkmans BA. Influence of HLA polymorphism on persistent remission in rheumatoid arthritis. Ann Rheum Dis 2002;61:351-3.

33 Möttönen T, Hannonen $\mathrm{P}$, Korpela $M$, Nissila $M$, Kautiainen $\mathrm{H}$, Ilonen J, et al. Delay to institution of therapy and induction of remission using single-drug or combination-disease-modifying antirheumatic drug therapy in early rheumatoid arthritis. Arthritis Rheum 2002;46:894-8.

34 Gough A, Faint J, Salmon M, Hassell A, Wordsworth P, Pilling D, et al. Genetic typing of patients with inflammatory arthritis at presentation can be used to predict outcome. Arthritis Rheum 1994;37:1166-70.

35 van Zeben D, Hazes JMW, Zwinderman AH, Cats A, Schreuder GM, D'Amoro J, et al. Association of HLA-DR4 with a more progressive disease course in patients with rheumatoid arthritis. Arthritis Rheum 1991;34:822-30.

36 Dougados M, Combe B, Cantagrel A, Goupille P, Olive P, Schattenkirchner M, et al. Combination therapy in early rheumatoid arthritis: a randomised, controlled, double blind 52 week clinical trial of sulphasalazine and methotrexate compared with the single components. Ann Rheum Dis 1999;58:220-5.

37 Möttönen $T$, Hannonen $P$, Leirisalo-Repo $M$, Nissila $M$, Kautiainen $H$ Korpela $M$, et al. Comparison of combination therapy with single-drug therapy in early rheumatoid arthritis: a randomised trial. FIN-RACo trial group. Lancet 1999;353:1568-73.

38 Möttönen T, Hannonen P, Korpela M, Nissila M, Kautiainen H, llonen J, et al. Delay to institution of therapy and induction of remission using single-drug or combination-disease-modifying antirheumatic drug therapy in early rheumatoid arthritis. Arthritis Rheum 2002;46:894-8.

39 Molenaar ET, Voskuyl AE, Dijkmans BA. Functional disability in relation to radiological damage and disease activity in patients with rheumatoid arthritis in remission. J Rheumatol 2002;29:267-70. 